\title{
Structural Stability Evaluation of Personnel Transfer Chamber Launch and Recovery System Winch Utilizing Finite Element Analysis
}

\author{
Seungchan Kim¹, Sang ki Lee², Moonkil Jeon², Taegyu Hwang', Jeonghwan Kim¹ \\ ${ }^{1}$ Korea Marine Equipment Research Institute \\ 435,Haeyang-ro, Yeongdo-gu, Busan, South korea \\ sckim@komeri.re.kr; poohgom81@gmail.com \\ ${ }^{2}$ Tech Flower Co., Ltd \\ 303-1213, Daedong-ro, Sasang-gu, Busan, South Korea
}

\begin{abstract}
The recovery system, which is the subject of this study, is installed in ships or offshore structures. This system is equipment that launches or recovers equipment and cargo. The load generated in the centrifuge recovery system causes damage to the parts and supports of the centrifuge recovery system. This can lead to serious problems when recovering. Therefore, it is necessary to examine the stability of the structure against the applied load. Verification is essential for the design phase.
\end{abstract}

Keywords: PTC (personnel transfer chamber), FEM (finite element analysis).

\section{Introduction}

The PTC recovery system is installed on a ship or an offshore structure to launch or recovery equipment and cargo. Due to the nature of the product, the ship runs up and down under sea conditions (Sea state 6: more than \pm 4 meters) under sea conditions due to the influence of wave during underwater operation because it is driven from deep and deep sea. Therefore, the acceleration of the heave and the surge which have a great influence on the ship is calculated by the load combination based on the data of "Ship Motion and Attitude, DOD- STD- 1399 (NAVY) SECTION 301A" was evaluated

\section{Structural analysis}

\subsection{Geometric and finite element models}

The winch of the true recovery system is the main winch and guide winch. These are the main devices of the PTC system. The geometric model and the finite element model of the main winch of the PTC recovery system are shown in Fig. 1 respectively. The finite element model was created as a 3-D 8-node structural solid type using the commercial program ANSYS.
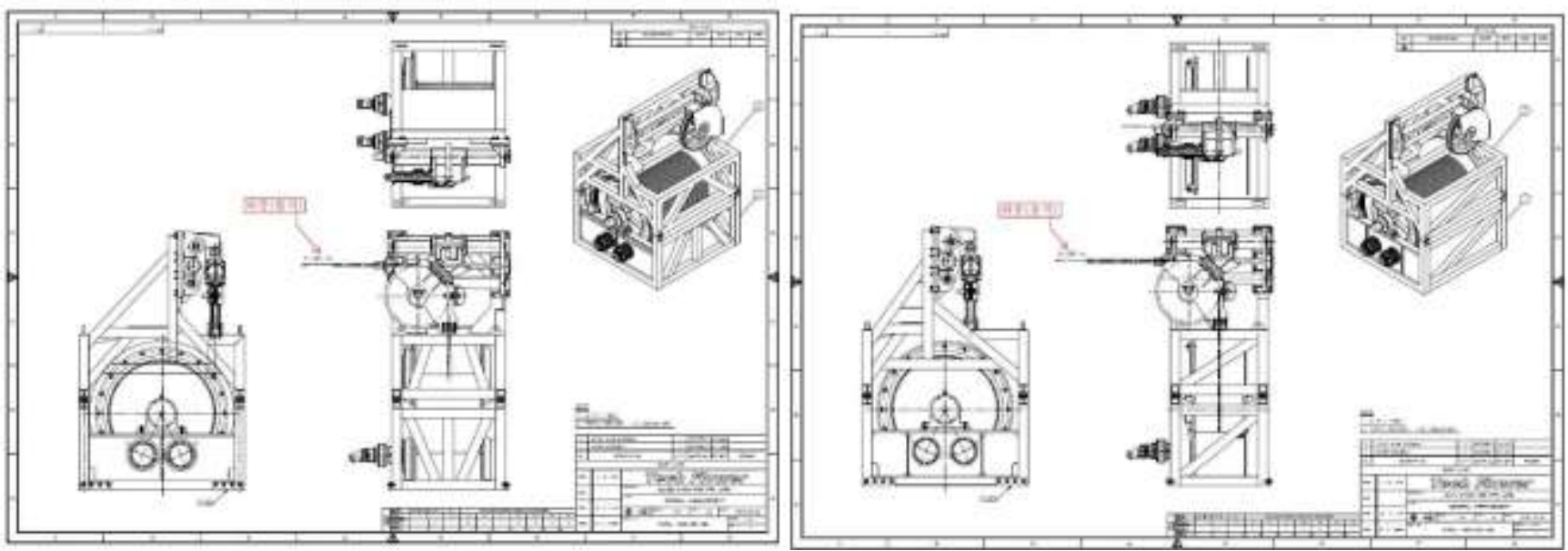

Fig. 1: Geometry model and F.E. model (Main winch \& guide winch). 

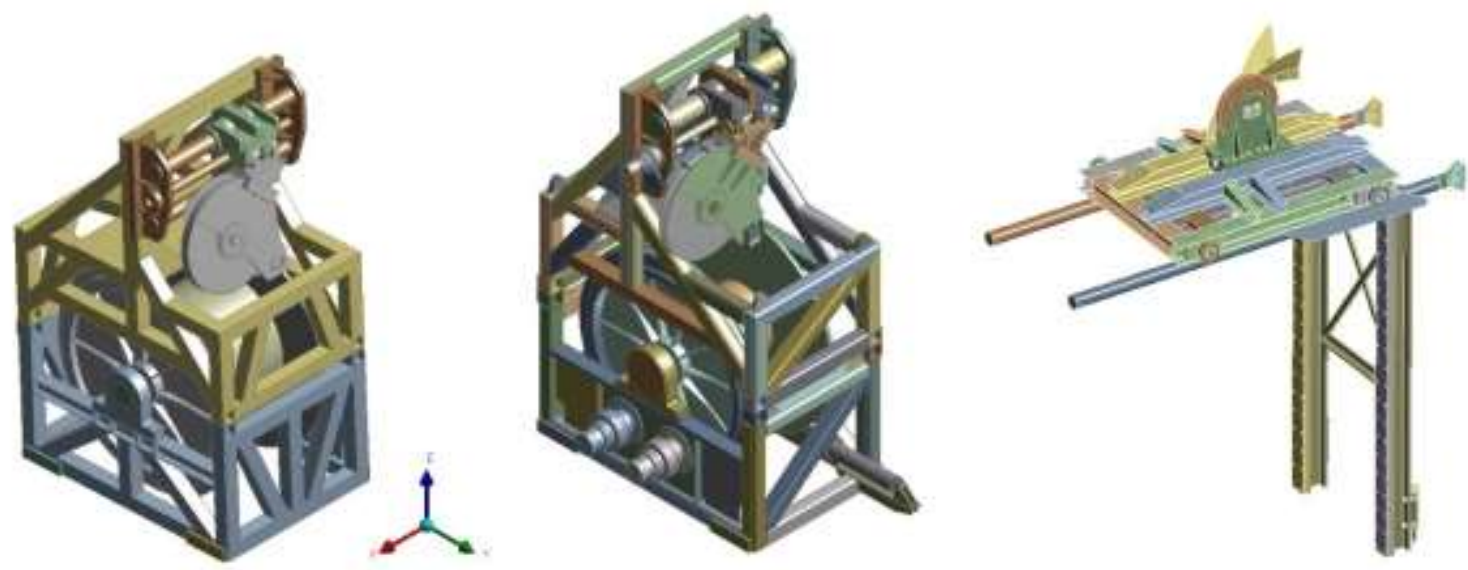

Fig. 2: Geometry model of ICT system (Main winch, guide winch and trolley).
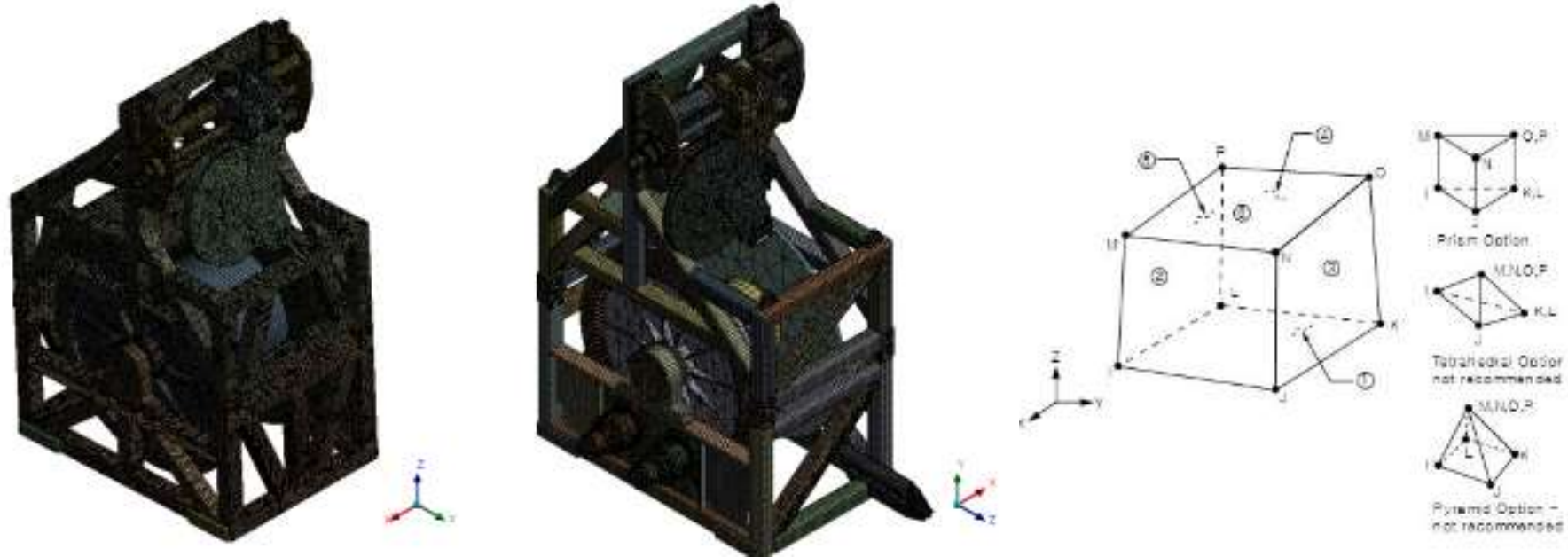

Fig. 3: F.E. model of ICT system (Main winch \& guide winch).

Table 1: Material properties.

\begin{tabular}{|c|c|c|c|c|}
\hline Component & $\begin{array}{c}\text { Density } \\
\left(\mathrm{kg} / \mathrm{m}^{3}\right)\end{array}$ & $\begin{array}{c}\text { young's modulus } \\
(\mathrm{MPa})\end{array}$ & Poisson's ratio & $\begin{array}{c}\text { Yield stress } \\
(\mathrm{MPa})\end{array}$ \\
\hline DRUM SHELL & 7850 & 200,000 & 0.3 & 353 \\
\hline PINS, GEAR, PINION & 7850 & 200,000 & 0.3 & 833 \\
\hline DRUM SHAFT & 7850 & 200,000 & 0.3 & 215 \\
\hline
\end{tabular}

\subsection{Sea state}

"Ship Motion and Attitude, DOD- STD- 1399 (NAVY) SECTION 301A"[1] shows different application acceleration depending on the sea condition. This shows the roughness of sea level waves divided into 10 grades. It is divided into classes in the World Meteorological Organization sea state code (WMO). In this study, the harshest conditions, the wave height above 14 meters, were applied. 


\begin{tabular}{|c|c|c|c|c|}
\hline \multicolumn{3}{|c|}{ State of the sea } & \multicolumn{2}{|r|}{ Swell } \\
\hline $\begin{array}{l}\text { Code } \\
\text { figure }\end{array}$ & $\begin{array}{l}\text { Height } \\
(m)\end{array}$ & Description & $\begin{array}{l}\text { Code } \\
\text { figure }\end{array}$ & Description \\
\hline 0 & 0 & Calm (glasy) & 0 & No swell \\
\hline 1 & $0-0.1$ & Calm (rippled) & 1 & Very low (short and low wave) \\
\hline 2 & $0.1=0.5$ & Smooth (waveless) & 2 & Low (long and low wave) \\
\hline 3 & $0.5-1.25$ & Slight: & $\mathbf{3}$ & Light (short and moderate wave) \\
\hline 4 & $1.25-2.5$ & Moderate & 4 & Moderate (werage and moderate wave) \\
\hline 5 & $2.5-4.0$ & Rough. & 5 & Moderate rough (long and moderate wave) \\
\hline 6 & $4.0-6.0$ & Very rough & 6 & Pough (short and heavy wave) \\
\hline 7 & $6.0-9.0$ & High & 7 & High (average and heary wave) \\
\hline 8 & $9.0-14.0$ & Veryhigh & 8 & Very hight (long and heany wave) \\
\hline 9 & Over 140 & Phenomenal & 9 & Confued (wave length and height indefinatle) \\
\hline
\end{tabular}

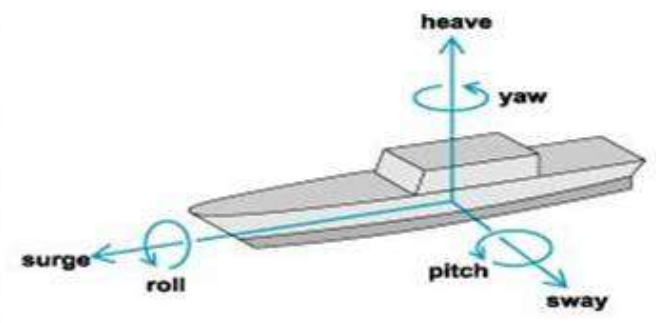

Fig. 4: The type of ship motion.

\subsection{Boundary Condition}

The boundary conditions of the true recovery system are fixed when the lower fixed part comes into contact with the vessel. Therefore, all the degrees of freedom were constrained in the lower fixed part of the analysis. The maritime state is a harsh condition, Sea State 8. At LBP 46-76 m, the Heave motion is $0.6 \mathrm{G}(\mathrm{G}=9.8 \mathrm{~m} / \mathrm{s})$ and the Surge motion is 0.3 . Therefore, three load conditions were combined to form and apply the same load case as Table 2. All degrees of freedom are restrained in the fixing area of the bottom of the winch.

Load $\mathrm{C}$ is applied by defining the weight and gravity density structure of each structure. Load D is the acceleration data of the vessel motion according to "Ship Motion and Attitude, DOD- STD-1399 (NAVY) SECTION 301A"[1]. This is shown in Table 3.

Table 2: Heave and surge motion parameters for calculation.

\begin{tabular}{|c|c|c|c|}
\hline Sea state & LBP meters & Heave acceleration $(\mathrm{g})$ & Surge acceleration $(\mathrm{g})$ \\
\hline \multirow{4}{*}{7} & less than 46 & 0.4 & 0.25 \\
\cline { 2 - 4 } & $46-76$ & 0.4 & 0.20 \\
\cline { 2 - 4 } & $76-107$ & 0.4 & 0.20 \\
\cline { 2 - 4 } & $107-152$ & 0.3 & 0.15 \\
\cline { 2 - 4 } & $107-152$ & 0.2 & 0.15 \\
\hline \multirow{5}{*}{8} & Greater than 213 & 0.2 & 0.10 \\
\cline { 2 - 4 } & less than 46 & 0.6 & 0.35 \\
\cline { 2 - 4 } & $46-76$ & 0.6 & 0.30 \\
\cline { 2 - 4 } & $76-107$ & 0.6 & 0.30 \\
\cline { 2 - 4 } & $107-152$ & 0.5 & 0.25 \\
\cline { 2 - 4 } & Greater than 213 & 0.4 & 0.25 \\
\hline \multirow{5}{*}{} & & 0.2 & 0.10 \\
\hline
\end{tabular}


Table 3: Load combination.

\begin{tabular}{|c|c|c|c|c|}
\hline Load & Main winch: Force(160,776N) & Main winch: Gravity(12,196kg) & \multicolumn{2}{|c|}{ Acceleration } \\
\cline { 3 - 5 } Case & Guide winch: Force(112,461N) & Guide winch: Gravity(17,000kg) & Vertical & Horizontal \\
\hline 1 & $\circ$ & 0 & & \\
\hline 2 & $\circ$ & 0 & - & \\
\hline 3 & 0 & 0 & + & + \\
\hline 4 & $\circ$ & 0 & - & + \\
\hline 5 & $\circ$ & 0 & + & - \\
\hline 6 & $\circ$ & 0 & - & - \\
\hline 7 & $\circ$ & 0 & & \\
\hline
\end{tabular}

\subsection{Analysis result}

The results of the structural analysis for ICT system winch shows the maximum stress though the all load cases. The maximum stress of the pins are 299.04MPa in load case5. This show the structure is satisfied the stress criteria.

The analysis results of the main winch are shown in Fig. $5 \sim$ Fig. 11
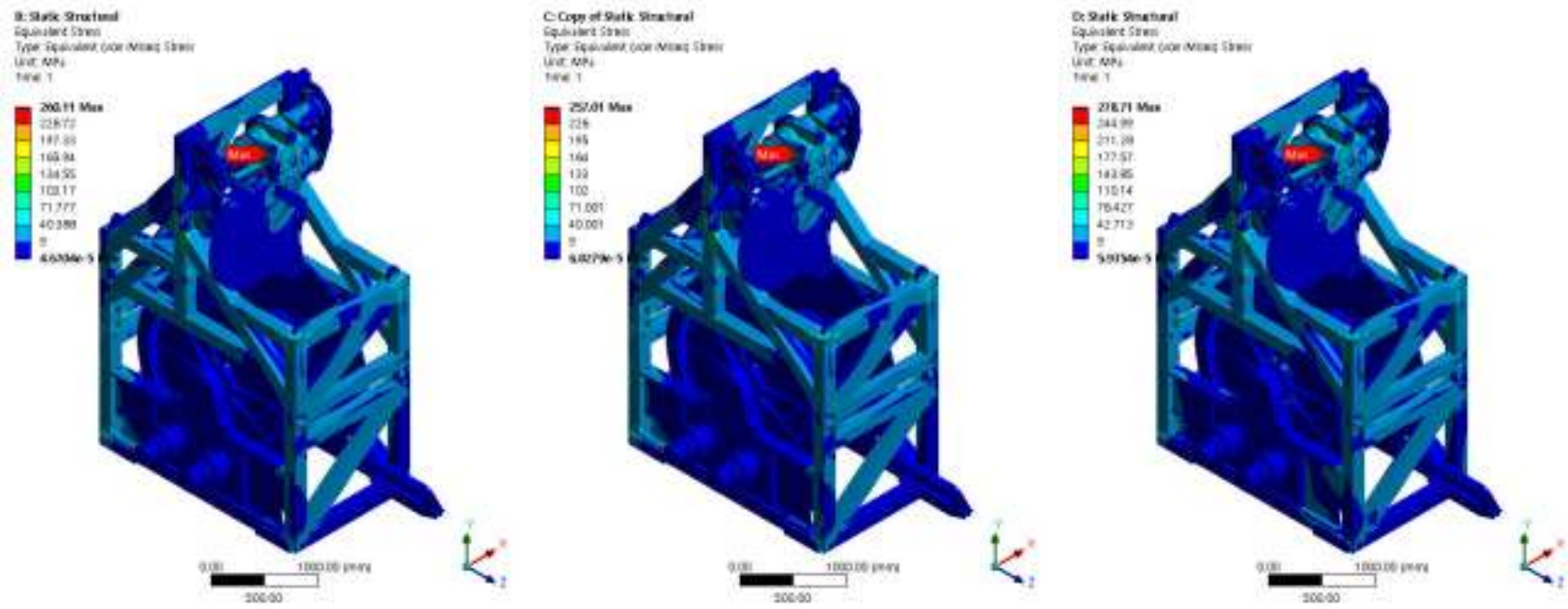

Fig. 5: Result of Equivalent Stress (LC1). Fig. 6: Result of Equivalent Stress (LC2). Fig. 7: Result of Equivalent Stress (LC3).
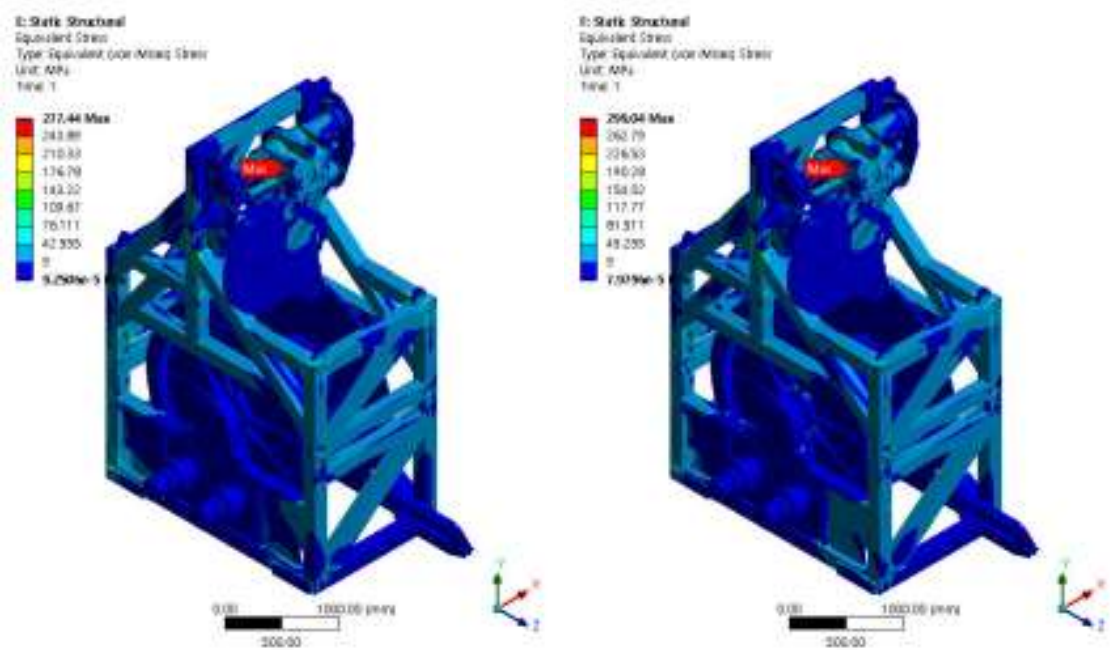

Fig. 8: Result of Equivalent Stress (LC4). Fig. 9: Result of Equivalent Stress (LC5). 

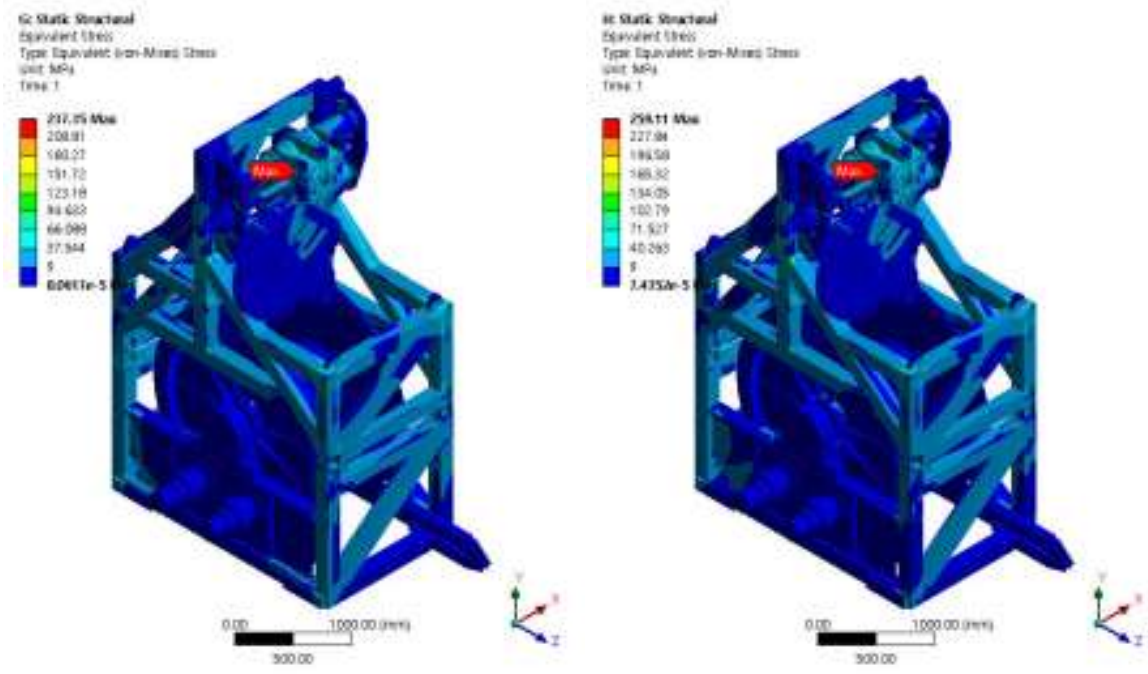

Fig. 10: Result of Equivalent Stress (LC6). Fig. 11: Result of Equivalent Stress (LC7).

Table 4: Result of PTC system main winch.

\begin{tabular}{|c|c|c|c|c|}
\hline Load Case & $\begin{array}{c}\text { Max. Eqv. Stress } \\
(\mathrm{MPa})\end{array}$ & $\begin{array}{c}\text { Yield Strength } \\
(\mathrm{MPa})\end{array}$ & Safety factor & Evaluation \\
\hline LC1 & 260.11 & 833 & 3.20 & O.K. \\
\hline LC2 & 257.01 & 833 & 3.24 & O.K. \\
\hline LC3 & 278.71 & 833 & 2.99 & O.K. \\
\hline LC4 & 277.44 & 833 & 3.00 & O.K. \\
\hline LC5 & 299.04 & 833 & 2.79 & O.K. \\
\hline LC6 & 237.35 & 833 & 3.51 & O.K. \\
\hline LC7 & 259.11 & 833 & 3.21 & O.K. \\
\hline
\end{tabular}

The analysis results of the guide winch are shown in Fig. $12 \sim$ Fig. 18
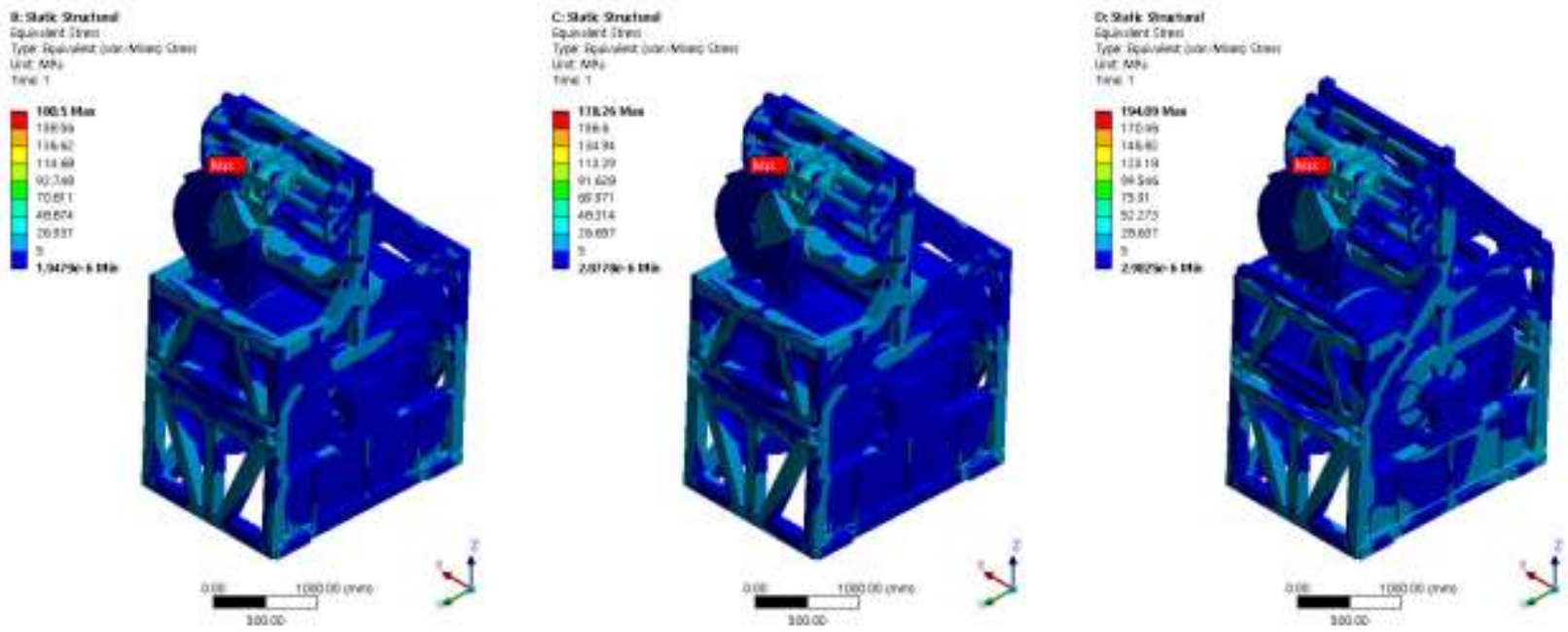

Fig. 12: Result of Equivalent Stress (LC1). Fig. 13: Result of Equivalent Stress (LC2). Fig. 14: Result of Equivalent Stress (LC3). 

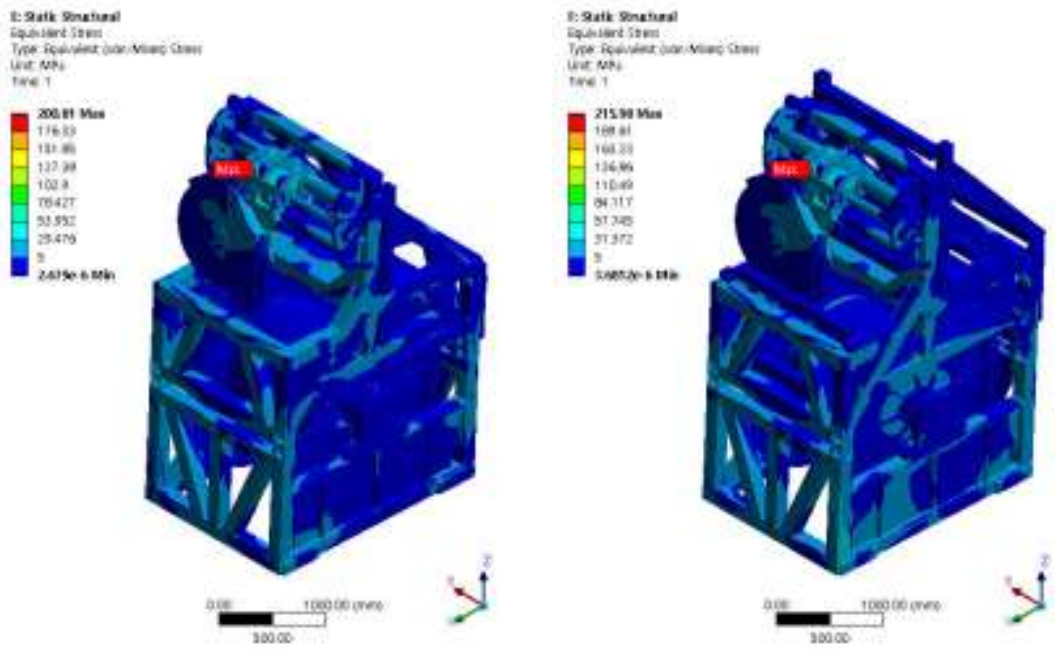

Fig. 15: Result of Equivalent Stress (LC4). Fig. 16: Result of Equivalent Stress (LC5).
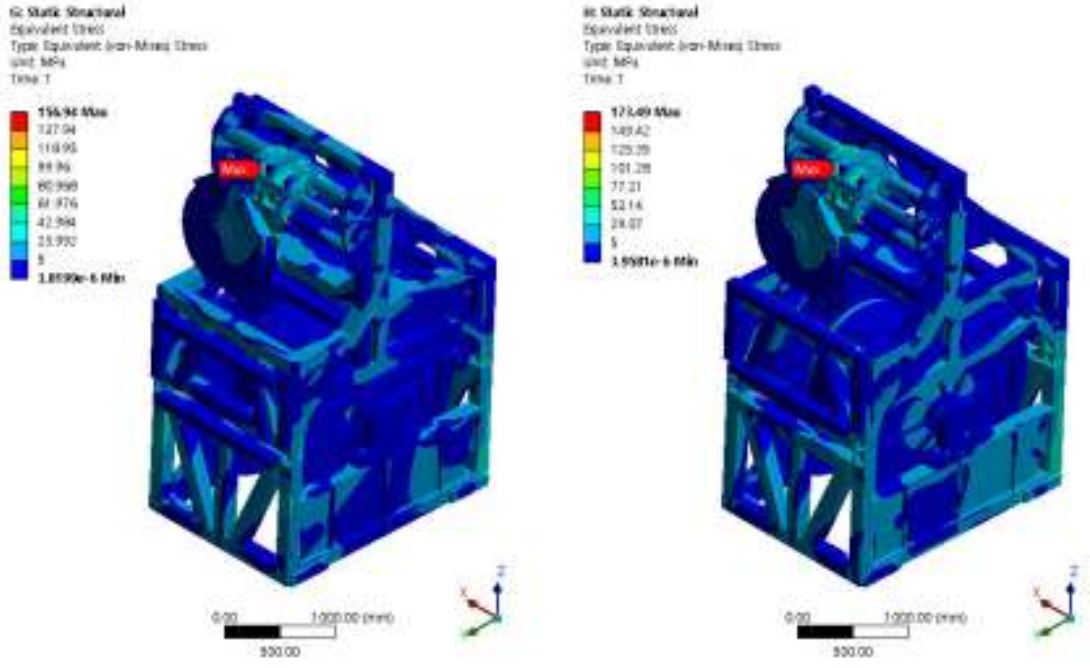

Fig. 17: Result of Equivalent Stress (LC6). Fig. 18: Result of Equivalent Stress (LC7).

Table 5: Result of PTC system guide winch.

\begin{tabular}{|c|c|c|c|c|}
\hline Load Case & $\begin{array}{c}\text { Max. Eqv. Stress } \\
(\mathrm{MPa})\end{array}$ & $\begin{array}{c}\text { Yield Strength } \\
(\mathrm{MPa})\end{array}$ & Safety factor & Evaluation \\
\hline LC1 & 180.50 & 833 & 4.61 & O.K. \\
\hline LC2 & 178.26 & 833 & 4.67 & O.K. \\
\hline LC3 & 194.09 & 833 & 4.29 & O.K. \\
\hline LC4 & 200.81 & 833 & 4.15 & O.K. \\
\hline LC5 & 215.98 & 833 & 3.86 & O.K. \\
\hline LC6 & 156.94 & 833 & 5.31 & O.K. \\
\hline LC7 & 173.49 & 833 & 4.80 & O.K. \\
\hline
\end{tabular}

\section{Conclusion}

In this study, the structural stability of sea conditions was reviewed. As a result of the analysis of a given load, the maximum stress within the yield strength. Therefore, it is judged that the structural stability has been secured. 


\section{Acknowledgements}

This work is supported by Korea Institute for Infrastructure Technology Advancement grant funded by Ministry of Trade

Industry on Energy, Infrastructure and Transport. (P0002161, the Localization Development of Launching and Recovery System Based on ICT)

\section{References}

[1] DOD- STD- 1399 (NAVY) SECTION 301A, 1986, "Ship Motion and Attitude", pp. 8.

[2] Seung Chan Kim, Sang hoon Kang, Joo Hyoung Choi, Jeong-Hwan Kim and Young Chul Park, 2016, "Structural Safety Evaluation for Fixed CO2 Extinguishing Systems Under Ship Motion," Trans. Korean Soc. Mech. Eng. C, vol. 4, no. 2 , pp. 75-83. 